\title{
Research on the renovation of Longtan Village in Guizhou Province based on spatial syntax
}

\author{
Yang $\mathrm{Xu}^{1, *}$, Ben Yuan ${ }^{1}$, Hui Zhang ${ }^{1}$ \\ ${ }^{1}$ College of civil engineering, architecture and environment, Hubei University of Technology, Wuhan, Hubei, 430071, China
}

\begin{abstract}
With the gradual deepening of National Rural Revitalization Strategy, investment, tourism of traditional natural villages has become a hot spot in recent years. Taking the traditional village renewal of the Longtan Village in Guizhou Province as an example, this paper uses the space syntax theory and method to establish axis model and horizon model by using Depthmap software to analyze the integration value, depth values, connection value and line of sight integration degree of Longtan Village street space, and to explore the method of scientifically and quantitatively guiding the project renewal and reshaping the vitality of traditional village street space.
\end{abstract}

\section{Introduction}

In October 2017, the 19th National Congress of the Communist Party of China put forward the "Rural Revitalization Strategy", and in March 2018, the general office of the State Council issued the guiding opinions on promoting the development of tourism in the whole region. Under this policy background, Longtan Village Reconstruction in Guizhou Province is a traditional settlement space renewal project aiming at developing whole area tourism, creating characteristic leisure, service function and characteristic village landscape. The traditional village of Longtan Village is in the Longtan scenic area of Anshun City, Guizhou Province, where the traffic is relatively closed and the regional economy is relatively backward. The traditional buildings, the texture of villages and streets and the natural environment are well preserved.

The concept of spatial syntax began in 1983 and was proposed by British scholar B. Hillier et al. ${ }^{[1]}$ Based on topological network structure and urban internal spatial form. The basic idea of space syntax theory is the spatial scale division and spatial segmentation, which usually uses the simplified axis diagram to express the spatial structure of the village. In this paper, space syntax theory is used to analyze the spatial form of Longtan Village. Through investigation and reference to the CAD drawing, axis model and horizon model are established by using Depthmap software to analyze the integration value, depth values, connection value and line of sight integration degree of street space in Longtan Village. The quantitative analysis of street space in Longtan Village is conducted to guide the scientific and rational perspective Objective renewal, reshape the vitality of the traditional village street space.

\section{General situations of Longtan Village}

Longtan Village is in the national 5A scenic area of Dragon Palace. There are many mountains in Longtan Village. There are only valleys and small pieces of flat land between the mountains. Most of the areas are between 1400-1600 meters above sea level. The terrain is undulating and the land utilization rate is low. It is mainly used for residential land.

\subsection{Current situation of streets and alleys in Longtan Village}

The streets and alleys of Longtan Village retain the characteristics of Bouyei people in the historical stage, which are rich in space and worth preserving. However, due to the lack of unified planning and management of streets and alleys, the addition, expansion, and collapse of some old houses seriously affect the continuity of street space and fire safety. Figure 1 is an aerial photo of the Village.

In the process of continuous transformation, the traditional old buildings are constantly replaced by new buildings. The existing roads are mixed with people and vehicles, the height difference of branch roads is large, and the guidance and accessibility are poor. At the same time, there is no interaction between the village and the scenic spot, and the surrounding water system is relatively separated from its streets and buildings, which needs to be integrated by design means.

\footnotetext{
* Corresponding author's e-mail: 20190013@hbut.edu.cn
} 


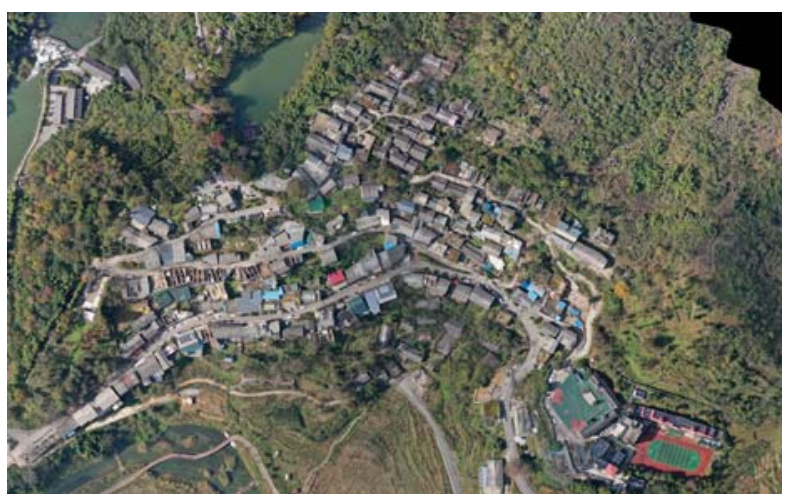

Figure 1. Aerial photo of village.

\subsection{Current situation of buildings in Longtan Village}

In Longtan Village, there is a relatively complete Buyei gathering place. The oldest building is about 150 years old. The main body of the Buyei traditional building is divided into two floors. The lower layer is built with masonry to form a cellar for raising livestock, which can also resist moisture. In addition to the traditional living space, there is an attic in the upper layer, which is accessed by the wooden stairs inside. The attic is naturally daylighting through the daylighting holes on the roof. (Figure 2)
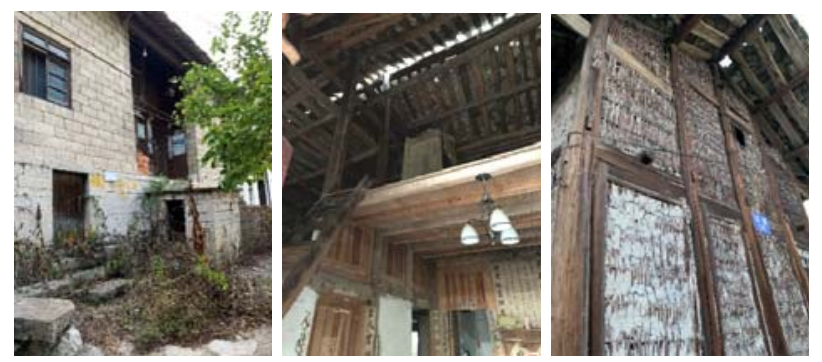

Figure 2. old building.

\section{Renovation methods}

As shown in Figure 3, the reconstruction adopts the combination of field investigation and spatial syntactic analysis, selects the space of the Longtan main lane and its branches, and explores the method and the feasibility of its vitality remodeling by combining spatial syntax analysis with practice. From the analysis of the parameters of the axis model, we have a more rational and intuitive understanding of the lane space in Longtan Village. From the perspective of current users, in the process of formulating the transformation plan, we discussed the details with the Management Office of Dragon Palace scenic area and Longtan Village residents.

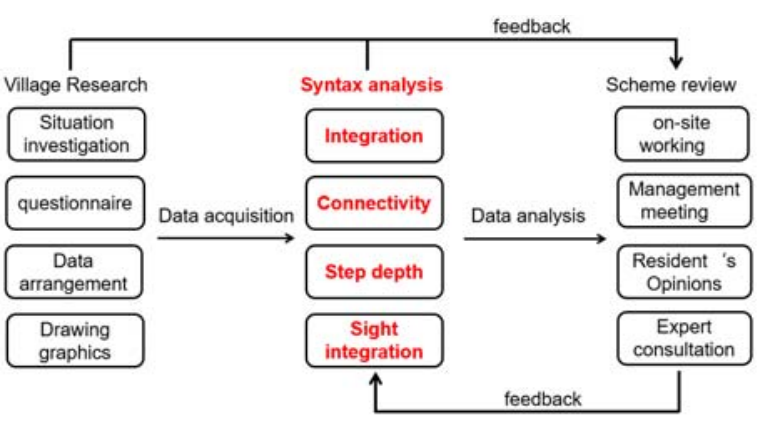

Figure 3. Renovation flow chart.

\section{A spatial syntax analysis of streets and alleys in Longtan Village}

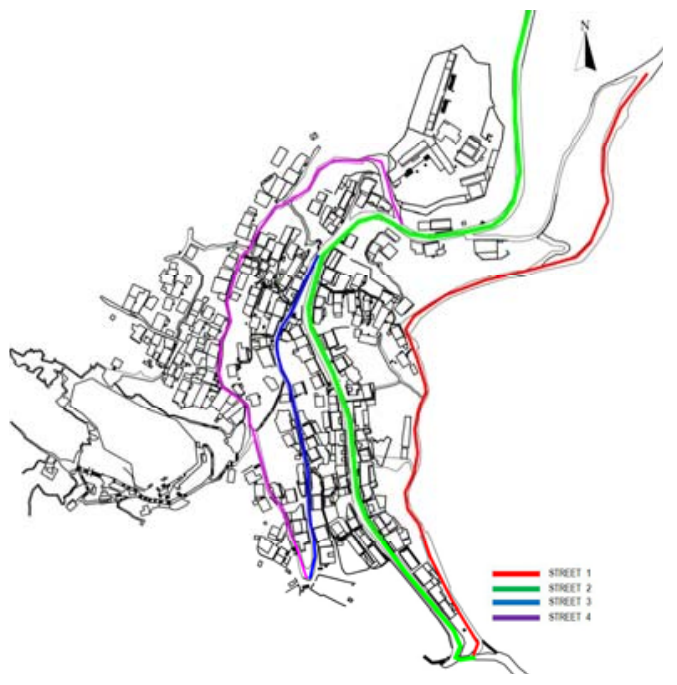

Figure 4. CAD of Longtan Village.

First, as shown in Figure 4, AutoCAD is used to process the general layout of the village, and the spatial texture of the streets and lanes is highly summarized. There are four streets of south to North named Street 1 4. The axis map of Longtan Village is established and imported into Depthmap for analysis. Then, through the axis map and visibility graph analysis, the spatial syntax Depthmap software is used to transform it into a quantifiable graphic language to analyze the relationship between the diagram and data, to express the characteristics of street space and its relationship with residents' activities. In the axis analysis model, the topological association between axes is quantified by mathematical model operation, and different axis colors indicate the size of variable values and the change of potential attributes ${ }^{[2]}$.

\subsection{Integration analysis}

The degree of integration represents the degree of agglomeration or dispersion between a certain space and other spaces in the system, and measures the potential of a space to attract arrival traffic ${ }^{[3]}$.

According to the analysis results of the global integration diagram, Longtan Village has three main local integration cores, and the value of the integration degree spreads from the center of the integration core to 
the surrounding areas (Fig. 5). In order to more intuitively analyze the relationship between the whole village and the street space, the plan of Longtan Village and the axis diagram of integration degree are superimposed to observe and analyze: (1) The integrated core 1 is the commercial entrance of Longtan Village, which creates a space with better accessibility and vision range, and people will stay in this place; (2) there are a large number of spontaneous B \& B buildings in the integrative core 2 Most of them will live here; (3) Integrated core 3 is the central square open space of the natural village, where villagers often gather for communication.

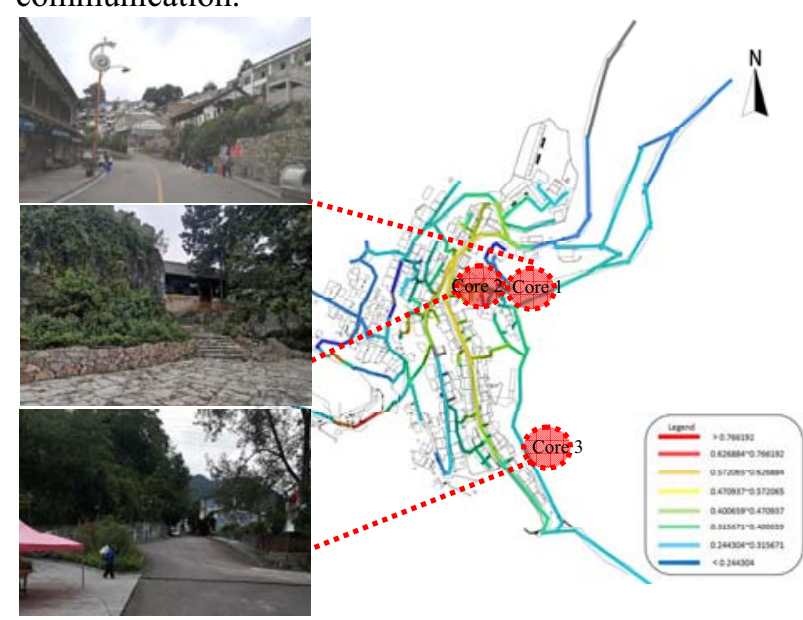

Figure 5. Integration analysis.

Through the comparison of field survey and data model analysis, we found that the spatial integration core location obtained by syntactic analysis has a high correlation with the public space location of villagers' actual activities and tourists' actual activities.

\subsection{Connectivity analysis}

The connection value represents the number of nodes in the system that intersect with other nodes. The higher the connection value, the closer the connection between the space and the surrounding, and the better the spatial permeability ${ }^{[4]}$.

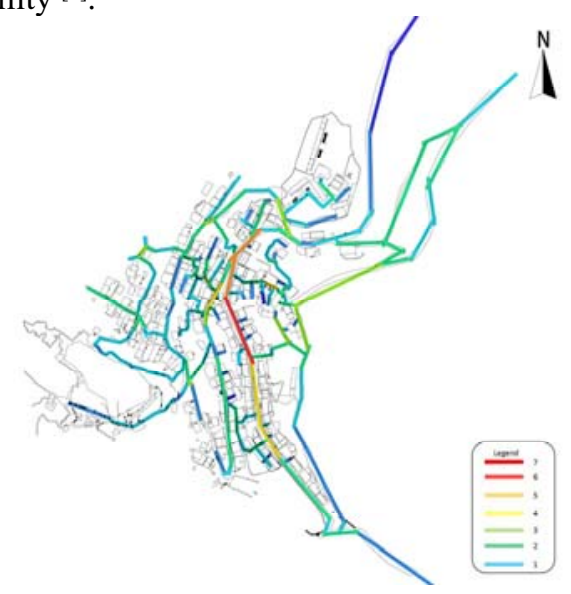

Figure 6. Connectivity analysis.

As can be seen from the connection value diagram (Figure 6), the highest connection value of Longtan
Village is the existing commercial street (street 2), followed by the entrance junction of street 2 and street 3 . After field investigation, it is found that the commercial street is the main traffic street in the village, and it is the main traffic road leading to the Dragon Palace scenic at the entrance of the village, with high frequency of use. In addition, the axis with high connection value is mostly north-south, which is basically consistent with the main growth and development direction of villages. But the connection value of residential streets behind the two main streets is generally not high.

\subsection{Step depth analysis}

The depth value represents the minimum number of connections that a space needs to go through to reach other spaces. The higher the depth value, the lower the potential for activity, and it is not easy to be selected when traveling ${ }^{[5]}$.

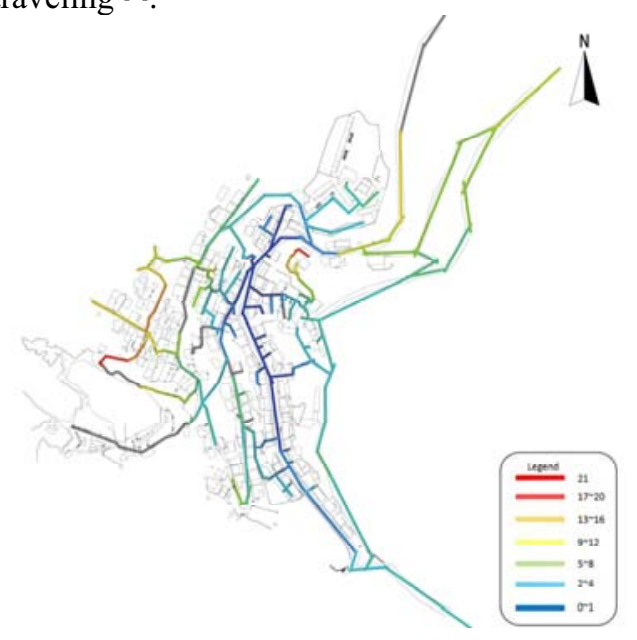

Figure 7. Step depth analysis.

In the depth analysis (Fig. 7), it is very important to reach the entrance space and the surrounding area of the commercial street where the depth value of the spatial integration core is small. These places have high accessibility and are closely related to the core space. This kind of street pattern helps to divide the flow of tourists, and has a better choice for their own purposes. At the same time, the depth of the Village Lane behind the two main streets is generally higher. According to the survey, this is the main street and lane of residents' life, far away from the main integrative core, forming a small internal traffic connection. This kind of village spatial layout not only helps to separate the activity area of tourists and residents, but also helps the villagers to communicate directly with each other.

\subsection{Sight integration analysis}

The visual environment around the landmark, landscape in the traditional village street space reflects the unique features of the village. To ensure the smooth visual environment can make people better understand and experience the space of the village streets ${ }^{[6]}$. 


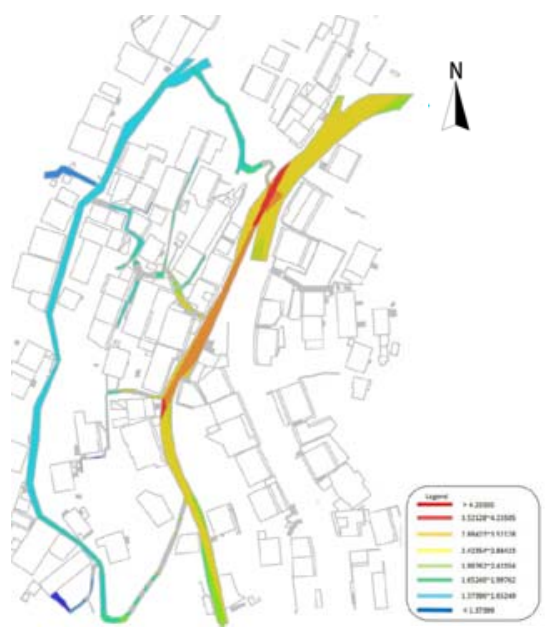

Figure 8. Sight integration analysis.

It can be seen from the analysis results of the street space line of sight of Longtan Village (Fig. 8), except for the two main street spaces of street 2 and street 3, the line-of-sight integration of each other is at a low level, which reflects that the main streets and lanes of Longtan Village are not closely connected with the original natural villages behind them. After investigation, it is found that the existing commercial street and the square and plank road at the entrance of Tianchi scenic area have low line of sight integration and little attraction, which cannot guide tourists well.

\section{Strategies for Street Renewal}

The difficulty of traditional natural village renewal lies in how to deal with the interaction among residents, tourists, villages, and scenic spots. On the one hand, the existing texture and pastoral lifestyle of the village attract people from other cities. On the other hand, the imperfect infrastructure has also caused a lot of inconvenience to modern people's life.

\subsection{Hierarchical renewal}

The planning and design highlight the organic renovation and renovation at different levels. Firstly, it pays attention to the preservation of the texture of traditional streets and alleys at the macro level, and then carries out the transformation in different regions at the meso level, to increase the accessibility of public space and protect the privacy of residents. Microscopically, it is the main objective to improve the buildings and other entities supporting facilities, and considering the space setting, cultural context, visual environment and entertainment and the continuation of the conversion.

Through field investigation, it is found that the software analysis results of spatial syntax are corresponding to the functions of streets, which is consistent with the development direction of village renewal. Street 2 is an existing commercial street with a high degree of integration. The design focuses on improving the current situation of mixed flow of people and vehicles and increasing the richness and interest of space. The integration degree of street 3 is the second, which can be transformed into the bar and B \& B functions of Street 2, and the connection between the two streets should be appropriately increased. The space integration degree of the East-West roadway behind the two main streets is low, and the line-of-sight integration is also low, which can keep the original architectural style and ensure that the life of the original residents will not be disturbed. Village renewal is not a complete transformation of tourist areas. While planning tourists to visit, it also increases the supporting facilities for the original residents, so that they can enjoy better life services, and achieve the work of tourism and historical village protection.

\subsection{Optimize street structure}

Longtan Village has a unique street space, but due to the lack of unified planning and management of streets and alleys, the addition, expansion, and collapse of some old houses seriously affect the continuity of street space and fire safety. Thence, it is necessary to sort out the existing order to the streets to improve the accessibility and utilization of streets and reduce costs to reach the core of overall space.

Table 1. Optimization of streets and lanes.

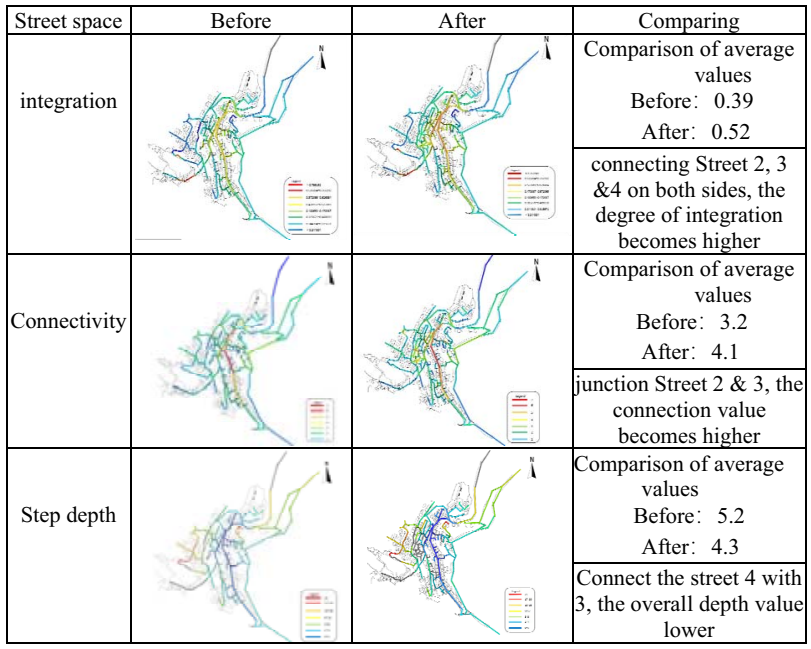

Because of the natural height difference between Street 2 and street 3, the direct connection between Street 2 and street 3 in horizontal space is blocked, so normal planning cannot be carried out in the middle of the street. Therefore, we choose to increase the internal connection between the residential area of street 3 and street 4, and appropriately increase the connection between the internal residential area and street 3. As shown in Table 1, after the transformation, the line-ofsight integration has been significantly improved, the depth of the layout is smaller, and the connection value is larger, so that the intersection of the line of sight of the internal residential buildings has a larger range, the traffic is more convenient and smoother, and the communication between residents has been greatly improved because of the connection of traffic and line of sight. 
Table 2. Optimization of streets and lanes.

\begin{tabular}{|c|c|c|c|c|c|c|}
\hline Ref & $\begin{array}{c}\text { Connectivity } \\
\text { (Before) }\end{array}$ & $\begin{array}{c}\text { Connectivity } \\
\text { (After) }\end{array}$ & $\begin{array}{c}\text { Integration } \\
\text { (Before) }\end{array}$ & $\begin{array}{c}\text { Integration } \\
\text { (After) }\end{array}$ & $\begin{array}{c}\text { Step Depth } \\
\text { (Before) }\end{array}$ & $\begin{array}{c}\text { Step Depth } \\
\text { (After) }\end{array}$ \\
\hline 0 & 6 & 7 & 0.703385 & 0.77917969 & 0 & 0 \\
\hline 1 & 7 & 7 & 0.670775 & 0.73538095 & 1 & 1 \\
\hline 2 & 5 & 6 & 0.62415445 & 0.68031341 & 2 & 2 \\
\hline 3 & 5 & 5 & 0.56769103 & 0.61477572 & 3 & 2 \\
\hline 4 & 3 & 4 & 0.51442653 & 0.55481029 & 4 & 4 \\
\hline 5 & 2 & 2 & \begin{tabular}{|l|l}
0.4694519 \\
\end{tabular} & 0.50472325 & 5 & 4 \\
\hline 6 & 3 & 4 & 0.43135145 & 0.46260351 & 6 & 5 \\
\hline 7 & 1 & 2 & 0.39805645 & 0.42613769 & 7 & 7 \\
\hline 8 & 2 & 2 & 0.39836091 & 0.42641547 & 7 & 6 \\
\hline 9 & 1 & 2 & 0.36979544 & 0.39523947 & 8 & 8 \\
\hline 10 & 2 & 2 & \begin{tabular}{|c|}
0.331018 \\
\end{tabular} & 0.35396177 & 10 & 9 \\
\hline 11 & 2 & 3 & 0.35348278 & 0.37854245 & 9 & 8 \\
\hline 12 & 1 & 1 & 0.31105199 & 0.33220991 & 11 & 10 \\
\hline 13 & 3 & 4 & \begin{tabular}{|l|}
0.378943 \\
\end{tabular} & 0.40653905 & 8 & 7 \\
\hline & & & & & & \\
\hline 154 & 2 & 3 & 0.30783504 & 0.318928 & 13 & 12 \\
\hline 155 & 3 & 4 & 0.29163319 & 0.30213457 & 14 & 14 \\
\hline 156 & 2 & 3 & 0.27675712 & 0.28676954 & 15 & 14 \\
\hline 157 & 2 & 2 & 0.26319197 & 0.27277789 & 16 & 15 \\
\hline 158 & 2 & 3 & 0.25077367 & 0.25998464 & 17 & 16 \\
\hline 159 & 2 & 3 & 0.23936437 & 0.24824339 & 18 & 17 \\
\hline 160 & 2 & 3 & 0.22884749 & 0.23743062 & 19 & 18 \\
\hline 161 & 1 & 1 & 0.21912363 & 0.22744136 & 20 & 18 \\
\hline 162 & 1 & 2 & 0.27602378 & 0.28614232 & 15 & 12 \\
\hline 163 & 4 & 5 & \begin{tabular}{|l|l}
0.4423413 \\
\end{tabular} & 0.45822862 & 8 & 9 \\
\hline 164 & 2 & 2 & 0.33560365 & 0.34756714 & 12 & 11 \\
\hline 165 & 3 & 3 & 0.35822344 & 0.3708171 & 11 & 10 \\
\hline 166 & 3 & 4 & 0.38312384 & 0.39655736 & 10 & 8 \\
\hline & & & & & & \\
\hline 227 & 1 & 1 & \begin{tabular}{|l|l}
0.5935691 \\
\end{tabular} & \begin{tabular}{|l|}
0.64732444 \\
\end{tabular} & 2 & 2 \\
\hline 228 & 1 & 2 & \begin{tabular}{|l|}
0.5935691 \\
\end{tabular} & 0.64732444 & 2 & 2 \\
\hline 229 & 2 & 2 & 0.46650863 & 0.49311823 & 6 & 6 \\
\hline 230 & 1 & 2 & 0.42780852 & 0.45189729 & 7 & 6 \\
\hline 231 & 2 & 4 & 0.36233521 & \begin{tabular}{|l|}
0.4443759 \\
\end{tabular} & 11 & 11 \\
\hline 232 & 1 & 3 & 0.33854851 & 0.47042167 & 12 & 10 \\
\hline 233 & 2 & 3 & 0.49370322 & 0.52225256 & 5 & 4 \\
\hline 234 & 1 & 2 & 0.45056823 & 0.47624415 & 6 & 5 \\
\hline 235 & & 5 & & 0.55107105 & & \\
\hline 236 & & 2 & & 0.5008586 & & \\
\hline 237 & & 1 & & 0.42283216 & & \\
\hline
\end{tabular}

As shown in Table 2 above, the optimization of spatial axis parameters analyzed by spatial syntax software is shown. We use spatial syntax to verify whether the sorted street pattern has destroyed the original traditional pattern of the village (Table 1). Before and after carding, the change of internal fabric relationship of street space can be judged by the change of spatial integration core position, reflecting the impact of carding on the overall space ${ }^{[7]}$. After comparison and analysis, the location and number of spatial integration cores have almost no change before and after carding, which indicates that the number and shape of streets and lanes before and after carding are different, but they are still similar to the original spatial fabric relationship of streets and lanes. While continuing the original traditional village street space structure, the average integration degree has increased, which improves the accessibility and efficiency of streets and alleys, to achieve the purpose of remodelling the space vitality of streets and lanes.

\subsection{Enhance public space}

The main communication core of the residents is around the integration core 1 and 2 . With the increase of mutual visibility between the main lane and the Branch Lane, the public space nodes of the village can be better displayed. (Fig. 9) since the core area of the IIC is biased towards street 4 , it will not be affected by street 3 , and it is more connected with the entrance and exit of street 3 and 4. The distance of residents from street 3 to their home is shorter, and the distance to the two central communication squares is shorter. The communication distance between neighbors is closer, which promotes communication and ensures that residents' life is not affected by the noise of street 3 . This improvement strategy not only increases the internal integration, but also improves the quality and efficiency of internal space.

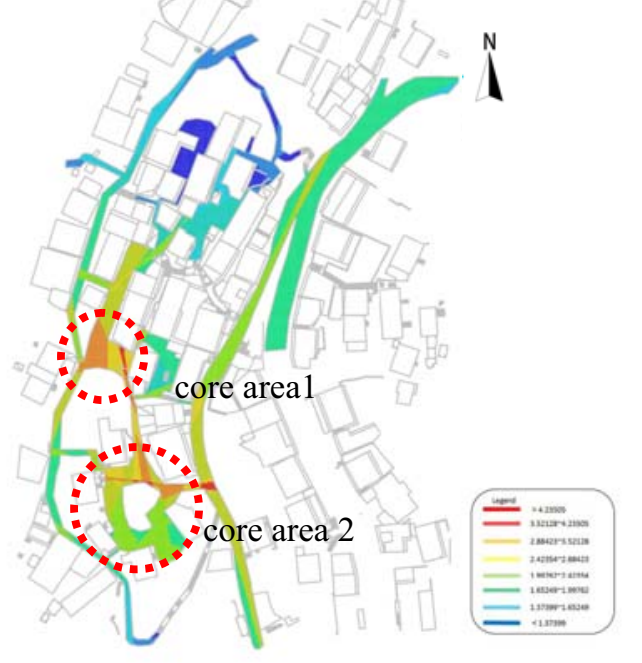

Figure 9 sight Integration after optimization.

From the perspective of perceptual experience, the factors that enhance the vitality of street space in villages include not only space itself, but also non-material factors, which cannot be reflected in spatial syntactic analysis. Therefore, the strategy of street space vitality reconstruction needs more in-depth theoretical research and practice. ${ }^{[8]}$

\subsection{Bottom-up renovation}

The charm of traditional villages lies in their diversity. Each village has its own appearance, which reflects the distinct regional characteristics. The living places in the traditional streets and alleys and the characteristic life style can be explained clearly by the residents. Therefore, the design team went deep into the residents' homes to conduct questionnaire survey, let the villagers themselves participate in the transformation, give full play to their respective advantages, and handle the relationship between protection and tourism development. This bottom-up renovation has also been actively supported by villagers, and gradually young people have joined the renewal team.

\section{Conclusion}

Traditional villages are important and valuable resources. Rural revitalization policies and targeted poverty alleviation policies have injected new vitality into the tourism development of traditional villages. However, the transformation of traditional villages is also faced with the situation of "one side of a thousand villages" and the disappearance of traditional features. Therefore, it is necessary to construct a reasonable hierarchical 
space transformation strategy at the beginning of village tourism development.

The application of spatial syntax analysis in the study of traditional rural street space enables us to explore the deep characteristics of rural street space and its relationship with human activities from a new perspective. Through computer analysis, it will be difficult to quantitatively describe the spatial structure, but can only be perceived by people, and realize the spatial organization of traditional village quantitative research. This paper hopes to use space syntax tools to directly describe the street space characteristics of traditional villages and find effective strategies to reshape the vitality of traditional villages.

\section{Acknowledgement:}

This work was financially supported by Major Projects of Science and Technology Department of Hubei Province (NO.2018ZYYD037).

\section{Reference:}

1. Hillier B, Vaughan L. The City as One Thing $[\mathrm{J}]$. Progress in Planning, 2007, 67(3): 205-230.

2. Hillier B, Hanson J. The Social Logic of Space [M]. Cambridge: Cambridge University Press, 1984.

3. Hillier B. Space is the Machine: A Configurational Theory of Architecture[M]. Cambridge: Cambridge University Press, 1996.

4. Duan Jin, Bill Hillier. Spatial syntax and urban planning [M]. Nanjing: Southeast University Press, 2007.

5. Duan Jin, Bill Hillier. Spatial syntax in China [M]. Nanjing: Southeast University Press, 2015.

6. Ruan Yisan, Xiang Bingjun. The protection and renewal of the old city neighborhoods in Suzhou [J]. Journal of urban planning, 1997 (4): 45-49.

7. Tao Wei, Chen Hongye, Lin Jieyong. Spatial morphology and cognition of traditional villages in Guangzhou from the perspective of syntax [J], Acta geographica Sinica, 2013 (2): 209-218.

8. Chen Libo, Liu guiran. Reconstruction of traditional village streets and lanes in xiongfan village, Dawu County in the context of spatial syntax [J]. Architecture and culture, 2020 (09): 206-210. 